\title{
Innovative collection development for e-books at the TU Delft Library
}

\author{
Zofia E. Brinkman Dzwig \\ TU Delft Library, The Netherlands
}

\begin{abstract}
Thanks to new technologies libraries worldwide go digital and are accessible 24/7 from remote locations.
The innovation is even more visible in traditional library tasks such as collection development and acquisitions. Those tasks are undergoing rapid transformation as well. One of the reasons is the current economic climate, leading to shrinking library budgets. The common "just in case" acquisition model becomes outdated. The TU Delft Library takes this challenge seriously and has a hybrid, "just in time" acquisition model, described in this paper.

The new model combines Patron Driven Acquisition (PDA), introduced by Ebook Library (EBL), with our current approval plans for paper books at Blackwell Book Services.

Our aim is to get our users involved in the collection development process, whilst maintaining our standard of service and controlling our budget in an efficient way.
\end{abstract}

Keywords: Collection development, demand driven acquisition, user participation, digital collection

In our rapidly changing world libraries cannot stand still. An academic library needs to survive in the middle of explosively growing information offer on one side, new technologies on the other side and last but not least new generations of library users, who expect libraries to be as modern and as flexible as the smartest ICT providers are.

This challenge has to be taken seriously. Thanks to new technologies, libraries worldwide go digital and can be accessed 24/7 from remote locations. They offer services on mobile devices and they are present in social media. Library innovation is even more visible in traditional tasks such as collection development and acquisitions.

To be able to compete in the information world, academic libraries have to address the following important issues:

- providing access to increasing content;

- a shift towards user driven library services and products;

- "just in time" acquisition models;

- shrinking library budgets.

Modern collection development is not any more about purchasing books and storing them on shelves the way it used to work in the age of paper books. Today the resources are mainly digital, available on remote servers. Managing digital resources means making choices between several business models. A collection manager's role is to optimize between factors like cost, access model and user's comfort.

My library, the TU Delft Library, worked out a unique solution to face challenges of the modern information world. It is a hybrid solution, combining traditional approval plans for paper books with patron driven acquisition ("PDA") for e-books.

To begin with: some background information about TU Delft Library. 
The TU Delft Library is the "National Technical Library" of the Netherlands. This status implicates that our book collection needs to be complete and up-to-date at all times, not only as a service to our own university students and researchers but also as a service to the outside world. In the past our collection was developed in the traditional way: we used to order paper books preselected by our subject librarians. In the late 90-ties, to avoid errors and gaps in the collection, we set up approval plans at Blackwell Book Services. In the age of mainly printed books this was a satisfactory solution for the library.

Today paper books are not our basic collection anymore. We already have a long tradition of collecting digital books. Our library started an e-policy back in 2003. When possible, we purchase a digital version of a title. Every year we buy more e-books than paper books.

At this moment the TU Delft Library has access to some 52,000 e-books from different providers. We do not digitize any paper books, we access all our e-books through several platforms (publishers and aggregators). All our e-titles can also be found in the library's catalogue (OPAC).

To explain our collection development policy let me begin with a few words about approval plans.

An approval plan is a set of profiles, regulating which books are automatically delivered to the library. The library needs to define all the main subjects to be covered (like chemical engineering, architecture and so on), to specify the more detailed sub subjects and non-subject parameters (like language, content level, price, list of relevant publishers and so on). Once the profiles have been defined, fine-tuned and tested, the preselected books will be delivered to the library. The book collection builds up in a structured manner and is always relevant and complete. The library is expected to purchase all the titles that are being delivered. The profiles need to be adjusted regularly by subject librarians. The work of book selectors is reduced to monitoring approval plans. The whole acquisitions process should fit into the library's yearly collection budget.

However: this traditional collection development model is outdated.

Maintaining a comprehensive, stand-by collection is quite expensive and what is more important: a substantial part of the purchased books will most certainly never be read. Why not? Because this is not a demand driven model. It is just a projection model based on selector's approach. The predefined selection will never completely match users' expectations. According to statistics some $40 \%$ of the library books never leave the shelf. We have verified that. It also means a waste of financial resources. In the current economic climate no academic library can afford to maintain a situation like this. Not just because of cost-effectiveness. Every collection needs to be evaluated and updated on a regular basis. Each item in the collection that is never used, is one item too much because it was purchased, processed and stored in vain.

A modern library must be better adjusted to the users' needs. It's time for a shift towards demand driven library services. What is often said is that users are not qualified enough to determine collection development. But collection development is a means to an end not an end in itself. We do not collect for ourselves, not to satisfy our ambitions nor to prove our skills. The purpose of a library is to provide services to its users.

In times of mainly digital resources, an item missing in the library collection can be instantly ordered, purchased and made available the very day it was ordered. There is no need to keep items in storage "just in case". Nowadays not only the e-books but also paper books can be purchased instantly.

In our new hybrid acquisition model we combine the structure of approval plans with new developments like PDA, involving both subject librarians and library users in the process of acquiring new books.

Here is our solution. 
In the classic PDA model metadata of the potentially interesting e-books are visible in the library's OPAC. The library however does not pay for those titles unless a user/patron shows interest. Depending on the PDA model, the library allows the user to borrow or to purchase a new title, with or without the librarian's mediation.

The problem with PDA seems to be how to control the whole process. A library does not want to buy one-sided subject collections, too expensive items or too many of them. Purchases should be evenly spread throughout the whole year. The PDA can lead to uncontrolled spendings and an unbalanced e-book collection.

In our approach we only load those metadata in our OPAC that are aligned with our approval plans. Like this we already pre-select our PDA titles. Blackwell and Ebook Library (EBL) work together on this model. Before sending us any paper books, Blackwell checks for each "approval title" if there also is a digital version available at the EBL. If not, we simply receive the paper book as we always did. If a digital version exists, the paper book will not be sent to us. Instead, Blackwell sends a message to EBL to put the title on our PDA list.

The PDA title set visible in our OPAC contains only those e-titles, that we would anyway have bought in print. Only this time we do not buy all those e-titles automatically, but we leave the purchase request to the user. Every request needs to be approved by a librarian.

Periodically we receive a list of new PDA metadata from EBL and we load the list in our OPAC. From here on it is just a classic mediated PDA. The difference between our solution and the classic PDA lies in the careful pre-selection and the de-duplication, which is being performed by Blackwell.

This concept looks simple and it really is. However in the pilot phase we encountered a few problems. Mainly because not every publisher can indicate in time for Blackwell if there is going to be a digital version available of a title.

In the end we still continue to collect books in a structured manner, but we purchase them "just in time" not "just in case". In fact it still is the library's choice. And with the pre-selection and the de-duplication available: do we still need mediation in this model?

Mediation is a built-in additional safety measure, because the model described above is not our only acquisition model. We also buy complete e-book packages from publishers like Springer, Elsevier, Wiley and we subscribe to aggregators like Knovel and Safari. We try out the Evidence Based Selection, another user-driven acquisition model. We need mediation to make sure we do not buy the same e-title through different channels. At this point we are experimenting with several models and we leave all our options open. If the process works as we expect it to work, we will probably skip the mediation step. In the future we intend to buy more e-books "title by title" with active participation of our users. Our aim is to get users involved in the collection development, whilst maintaining our standard of service and controlling our budget in an efficient way.

Why is our new acquisition model advantageous for our library?

- The quick gain lies in the instant availability of digital titles for the user while ensuring that the content fits in the library profile.

- Not all the "approval titles" need to be purchased in advance.

- Keeping the collection relevant and up to date whilst staying cost-efficient.

- No financial risk.

Last but not least: in spite of all new challenges that we have to face, this model still allows us to fulfil our role as the "National Library".

And yes, because it's so new, we find ourselves setting out the trail! 